\title{
Neuro-Behcet's disease in a case with papilledema and intracranial hypertension as the initial presentation
}

\author{
Sevda Aydin Kurna, ${ }^{1}$ Ahmet Altun, ${ }^{1}$ Necati Cakir, ${ }^{2}$ Aysu Karatay Arsan ${ }^{3}$ \\ ${ }^{1}$ Department of Ophthalmology, Fatih Sultan Mehmet Training and Research Hospital, Istanbul, Turkey \\ 2Department of Rheumatology, Fatih Sultan Mehmet Training and Research Hospital, Istanbul, Turkey \\ 3Department of Ophthalmology, Kartal Lütfü Kırdar Training and Research Hospital, Istanbul, Turkey
}

\begin{abstract}
A 27-year-old female presented to the Clinic of Ophthalmology with the complaints of photophobia, headache, and diplopia. An ophthalmological examination indicated that her best-corrected visual acuity was 20/20 in both eyes with decreased contrast sensitivity. Fundoscopic examination revealed bilateral papilledema. The cerebrospinal fluid opening pressure was above normal at $38.5 \mathrm{~cm} \mathrm{H}_{2} \mathrm{O}$. Cranial magnetic resonance imagining venography revealed left lateral sinus thrombosis and right lateral sinus retardation of filling. Based on her history, laboratory tests, and neuro-imaging findings, she was diagnosed with vascular neuro-Behcet's disease (NBD). It is important to consider NBD in the differential diagnosis of patients with bilateral papilledema and intracranial hypertension.
\end{abstract}

Keywords: Intracranial hypertension; neuro-Behcet's disease; papilledema.

Cite this article as: Aydin Kurna S., Altun A., Cakir N., Karatay Arsan A. Neuro-Behcet's disease in a case with papilledema and intracranial hypertension as the initial presentation. North Clin Istanb 2018;5(2):153-156.

$\mathrm{B}$ ehcet's disease (BD) is an inflammatory multisystem disease described by Hulusi Behcet in 1937 [1]. According to the International Study Group's classification, a definitive diagnosis of $\mathrm{BD}$ requires recurrent oral ulcerations plus two of the following: recurrent genital ulcerations, skin lesions, eye lesions, and a positive pathergy test [2]. The diagnostic criteria for neuro-Behcet's disease (NBD) is a current diagnosis of BD plus the presence of neurological symptoms not otherwise explained by known systemic or neurological diseases $[3,4]$. NBD has variable prevalence depending on the series but can represent around $5 \%-10 \%$ of the affected patients in a large series $[5,6]$.

In this report, we would like to present a case of NBD with an unusual initial presentation of papilledema and intracranial hypertension and emphasize on NBD as a rare but important cause of bilateral papilledema due to intracranial hypertension.

\section{CASE REPORT}

A 27-year-old female presented to the Fatih Sultan Mehmet Education and Research Hospital Ophthalmology Clinic with the complaints of photophobia, headache, and diplopia since 10 days. On ophthalmological examination, her best-corrected visual acuity (BCVA) was 20/20, with decreased contrast sensitivity in both eyes. Anterior segment examination, extraocular movements, and intraocular pressures were within normal limits. Fundoscopic examination revealed bilateral

Received: March 18, 2017 Accepted: September 30, 2017 Online: April 17, 2018

Correspondence: Dr. Sevda AYDIN KURNA. Department of Ophthalmology, Fatih Sultan Mehmet Training and Research Hospital, Istanbul, Turkey.

Tel: +90 21657830 00/3715 e-mail: sevdaydin@yahoo.com

(c) Copyright 2018 by Istanbul Provincial Directorate of Health - Available online at www.northclinist.com 

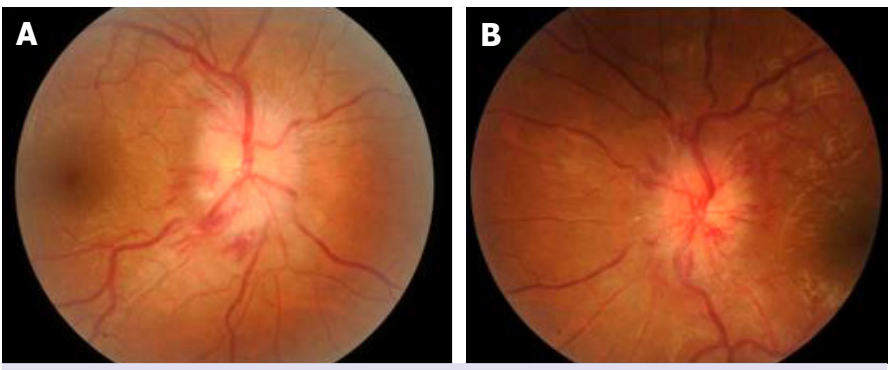

FIGURE 1. Papilledema and peripapillary small hemorrhages in the right eye (A) and left eye at presentation (B).
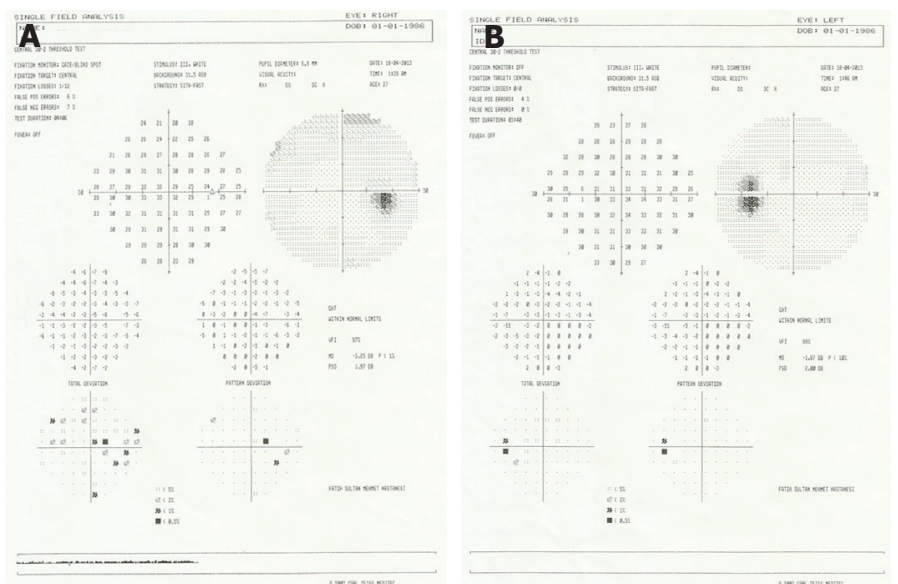

FIGURE 2. Enlarged blind spots in the visual fields in the right eye (A) and the left eye (B) at presentation.

papilledema and peripapillary small hemorrhages with normal retinal and macular appearance (Fig. 1 A, B). There were enlarged blind points in the visual field of both eyes measured with automated perimetry (Swedish Interactive Threshold Algorithm standard 30-2 strategy, Humphrey Visual Field Analyzer; Carl Zeiss Meditec, Dublin, CA) (Fig. 2 A, B).

Laboratory test revealed elevated erythrocyte sedimentation rate and C-reactive protein level. Laboratory work-up regarding infectious diseases was negative. Cranial magnetic resonance imagining (MRI, 3 tesla) venography revealed dominancy in the internal jugular vein and transverse and sigmoid sinuses with left lateral sinus thrombosis and right lateral sinus retardation of filling. The opening pressure of the cerebrospinal fluid was 38.5 cm $\mathrm{H}_{2} \mathrm{O}$ (Normal value: $10-18 \mathrm{~cm} \mathrm{H}_{2} \mathrm{O}$ ) when she was lying on side, with no microscopic findings.

The patient had no systemic risk factors such as diabetes mellitus, hypertension, or hyperlipidemia. She
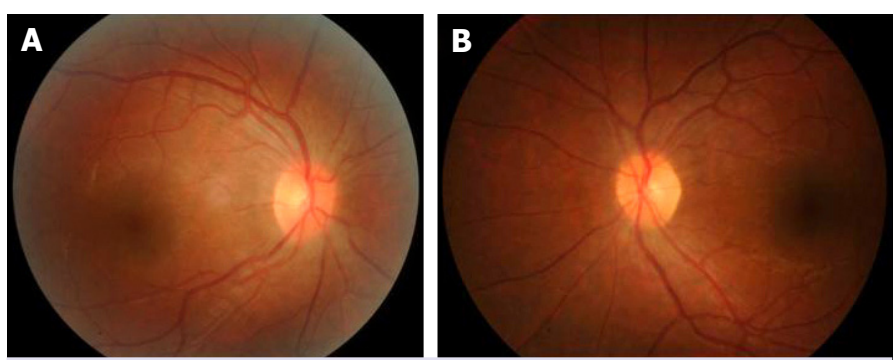

FIGURE 3. Normal optic disc appearence after treatment in the right eye (A) and the left eye (B).
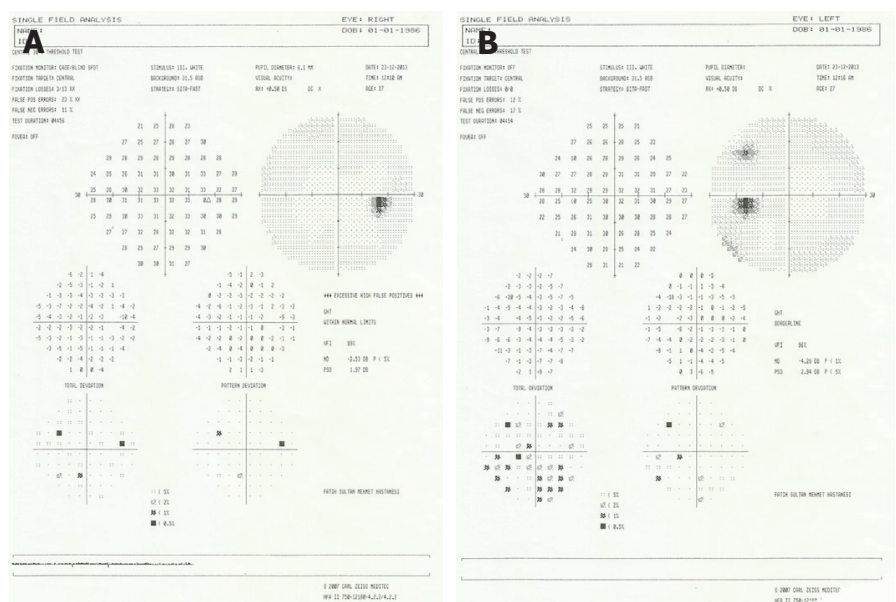

FIGURE 4. Visual field showed a normal pattern on the right side $(A)$ with a minimal enlargement of the blind spot on the left side (B).

had smoked for 8 years but not consumed alcohol before. According to the history obtained from the patient, she had recurrent oral and genital ulcerations of an unknown etiology for 9 years. She had a positive family history of Behcet's disease. Physical examination revealed multiple genital scar lesions due to previous ulcers and was otherwise unremarkable. Pathergy test was negative. She was positive for HLA-B51. According to her history, laboratory tests, and neuro-imaging findings, she was diagnosed with vascular NBD.

The patient was hospitalized in the Rheumatology Clinic and administered a medical treatment comprising systemic pulse intravenous methylprednisolone (1000 $\mathrm{mg} /$ day) for 5 days and oral acetazolamide $250 \mathrm{mg}$ tablet $2 \times 2 /$ day. Subsequently, the patient started using oral $30 \mathrm{mg} /$ day prednisolone for 1 month, with a tapering scheme of $2.5 \mathrm{mg}$ every week afterward, and azathioprine $50 \mathrm{mg} 3 \times 1$ for 2 years. 


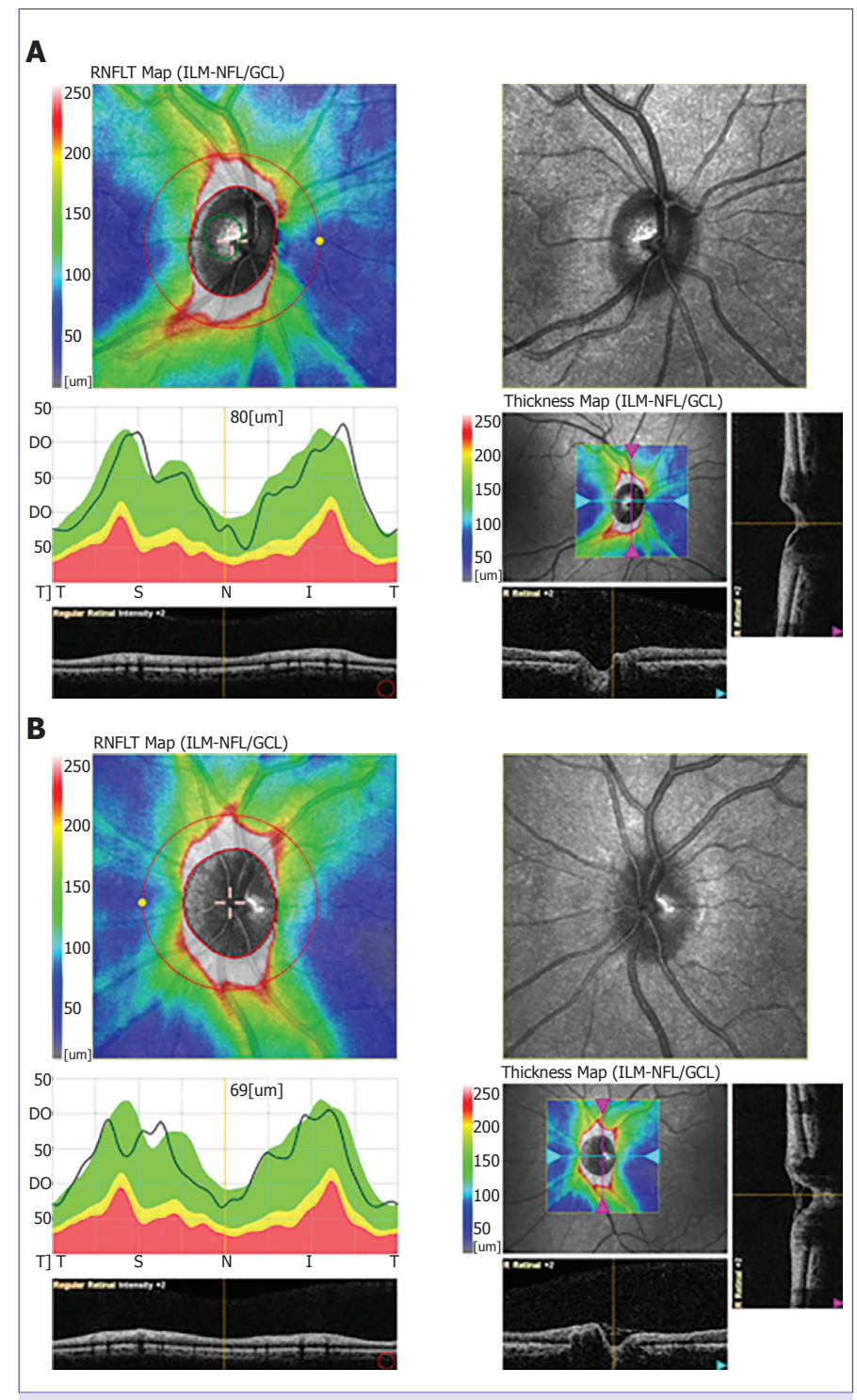

FIGURE 5. Optical coherence tomography of the optic nerve was normal on the right side $(A)$, whereas there was a membrane over the optic disc on the left side after 1 year (B).

Patient's symptoms and fundoscopic findings were regressed on the second day of the treatment. At the firstmonth control examination, optic discs appeared normal without edema and hemorrhage (Fig. 3 A, B), BCVA was $20 / 20$ in both eyes, contrast sensitivity improved to normal levels, and opening pressure of cerebrospinal fluid was $14.5 \mathrm{~cm} \mathrm{H}_{2} \mathrm{O}$. At the 8th month visit of the patient, visual field showed a normal pattern on the right side with a minimal enlargement of the blind spot on the left side (Fig. 4 A, B). Optical coherence tomography (OCT) of the optic nerve was normal on the right side, whereas there was a membrane over the optic disc on the left side (Fig. 5 A, B).

\section{DISCUSSION}

$\mathrm{BD}$ is a systemic inflammatory disorder for which the underlying histopathology is an occlusive vasculitis. Ocular participation occurs in about $70 \%$ of patients, typically in the form of a relapsing-remitting uveitis [7]. The mean age of onset for BD and NBD was found to be $26.7 \pm 8.0$ and $32.0 \pm 8.7$ years, respectively $[6,8]$. Neurological involvement in BD occurs more commonly in men, with a male to female ratio of up to $4: 1$ [3]. Our case was a 27-yearold female who reported a history of recurrent oral and genital ulcerations.

NBD can be diagnosed if there is central nervous system involvement and the BD diagnostic criteria are satisfied. It is quite common in adult patients and occurs rarely during childhood and adolescence. Young patients may share symptoms and signs of NBD with other neuro-ophthalmological disorders (e.g., idiopathic intracranial hypertension), thus making the differential diagnosis difficult. Neuro-imaging is mandatory and necessary for a correct NBD diagnosis [9]. The radiological pattern of NBD has been divided into two major forms: parenchymal and non-parenchymal (vascular) forms. Neurological involvement in BD is usually presented as brainstem disturbance, meningomyelitis, and palsy involving cranial nerves VI and VII, although cerebral venous sinus thrombosis is seen in $10 \%-20 \%$ of the cases of NBD $[5,6]$.

Our case had nonparenchymal (vascular) NBD because there was vascular evidence on MRI venography. In nonparenchymal NBD, cerebral venous thrombosis (CVT) may cause increased intracranial pressure with severe headache, mental changes, and motor ocular cranial nerve palsies. Among a cohort of 820 patients with BD, CVT was present in $64(7.8 \%)$. BD patients with CVT had lower parenchymal central nervous system involvement and higher extraneurologic vascular lesions. Severe visual loss due to optic atrophy was the main complication of CVT that was observed in $15 \%$ of the patients. In multivariate analysis, papilledema and concurrent prothrombotic risk factors were independently associated with the occurrence of sequelae [10]. Our case had elevated intracranial pressure and papilledema, but she had only severe headache and diplopia without any mental change, cranial nerve palsy, or visual loss.

The cerebrospinal fluid in NBD is normal in $40 \%$ of cases. In cases where changes are noticed in the cerebrospinal fluid, mild pleocytosis, mildly elevated protein levels, and oligoclonal bands may be observed [11]. Our 
case had elevated cerebrospinal fluid pressure with no microscopic findings.

Akman-Demir et al. reported a large NBD study in 1999 [5]. According to their study, only a minority of patients exhibited neurological features without evident systemic disease: 15 cases (8\%) exhibited a neurological onset concomitant with BD onset and 6 cases $(3 \%)$ exhibited neurological disease prior to the occurrence of other BD features. There are a few cases in the literature documenting cerebral vein thrombosis and papilledema or cranial hypertension as the first manifestation in $\mathrm{BD}$ patients [12-14].

The most common visual field defects in the patients with idiopathic intracranial hypertension, also known as pseudotumor cerebri, are enlargement of the blind spot and diffuse visual field loss at presentation [15]. Our case showed bilateral enlargement of the blind spot in the presentation, which improved at 1 month. Visual field showed a normal pattern with a minimal enlargement of the blind spot on the left side after 1 year; OCT of the optic nerve was normal on the right side, whereas there was a membrane over the optic disc on the left side possibly explaining the minimal enlargement of the blind spot on the left side observed at the last visit.

In conclusion, in this report, we want to emphasize the importance of considering NBD in the differential diagnosis when patients present with bilateral papilledema and intracranial hypertension.

Conflict of Interest: No conflict of interest was declared by the authors.

Financial Disclosure: The authors declared that this study has received no financial support.

Authorship contributions: Concept - S.A.K., A.A., N.C., A.K.A.; Design - S.A.K., A.A., N.C., A.K.A.; Supervision - N.C., A.K.A.; Materials - S.A.K.; Data collection \&/or processing - S.A.K., N.C.; Analysis and/or interpretation - S.A.K., N.C., A.A.; Writing - S.A.K., A.A., N.C.; Critical review - S.A.K., A.A., N.C., A.K.A.

\section{REFERENCES}

1. Behçet, H. Uber rezidivierende Aphthose, durch ein Virus verursachte Geschwure am Mund, am Auge und an den Genitalien. Derm Wochenschrift 1937;105:1152-7.

2. Criteria for diagnosis of Behçet's disease. International Study Group for Behçet's Disease. Lancet 1990;335:1078-80.

3. Siva A, Altintas A, Saip S. Behçet's syndrome and the nervous system. Curr Opin Neurol 2004;17:347-57. [CrossRef]

4. Kalra S, Silman A, Akman-Demir G, Bohlega S, Borhani-Haghighi A, Constantinescu CS, et al. Diagnosis and management of NeuroBehçet's disease: international consensus recommendations. J Neurol 2014;261:1662-76. [CrossRef]

5. Akman-Demir G, Serdaroglu P, Tasçi B. Clinical patterns of neurological involvement in Behçet's disease: evaluation of 200 patients. The Neuro-Behçet Study Group. Brain 1999;122:2171-82. [CrossRef]

6. Siva A, Kantarci OH, Saip S, Altintas A, Hamuryudan V, Islak C, et al. Behçet's disease: diagnostic and prognostic aspects of neurological involvement. J Neurol 2001;248:95-103. [CrossRef]

7. Deuter CM, Kötter I, Wallace GR, Murray PI, Stübiger N, Zierhut M. Behçet's disease: ocular effects and treatment. Prog Retin Eye Res 2008;27:111-36. [CrossRef]

8. Saip S, Akman-Demir G, Siva A. Neuro-Behçet syndrome. Handb Clin Neurol 2014;121:1703-23, [CrossRef]

9. Mora P, Menozzi C, Orsoni JG, Rubino P, Ruffini L, Carta A. NeuroBehçet's disease in childhood: a focus on the neuro-ophthalmological features. Orphanet J Rare Dis 2013;8:18. [CrossRef]

10. Saadoun D, Wechsler B, Resche-Rigon M, Trad S, Le Thi Huong D, Sbai A, et al. Cerebral venous thrombosis in Behçet's disease. Arthritis Rheum 2009;61:518-26. [CrossRef]

11. Hirohata S, Kikuchi H, Sawada T, Nagafuchi H, Kuwana M, Takeno $\mathrm{M}$, et al. Clinical characteristics of neuro-Behcet's disease in Japan: a multicenter retrospective analysis. Mod Rheumatol 2012;22:405-13.

12. Lizarazo-Barrera JC, Jacobelli S, Mellado P, González S, Massardo L. Extensive cerebral vein thrombosis as first manifestation of Behçet's disease. Report of one case. Rev Med Chil 2010;138:746-51.

13. Ascaso FJ, Rodriguez A, Cristóbal JA. Cranial hypertension as first manifestation of Behçet's disease: a case report. Doc Ophthalmol 2002;105:291-9. [CrossRef]

14. Ginés MA, Jaber I, Pérez J, Estrada RV. Papilledema as the first manifestation of Behçet's disease. An Med Interna 1996;13:255-6.

15. Rebolleda G, Muñoz-Negrete FJ. Follow-up of mild papilledema in idiopathic intracranial hypertension with optical coherence tomography. Invest Ophthalmol Vis Sci 2009;50:5197-200. [CrossRef] 